\title{
Comparison of five equations for estimating resting energy expenditure in Chinese young, normal weight healthy adults
}

\author{
Zhi-yong Rao ${ }^{1,2}$, Xiao-ting Wu'2, Bin-miao Liang ${ }^{3}$, Mao-yun Wang ${ }^{3}$ and Wen Hu${ }^{1 *}$
}

\begin{abstract}
Background: Most resting energy expenditure (REE) predictive equations for adults were derived from research conducted in western populations; whether they can also be used in Chinese young people is still unclear. Therefore, we conducted this study to determine the best REE predictive equation in Chinese normal weight young adults.

Methods: Forty-three (21 male, 22 female) healthy college students between the age of 18 and 25 years were recruited. REE was measured by the indirect calorimetry (IC) method. Harris-Benedict, World Health Organization (WHO), Owen, Mifflin and Liu's equations were used to predictREE (REEe). REEe that was within $10 \%$ of measured REE (REEm) was defined as accurate. Student's $t$ test, Wilcoxon Signed Ranks Test, McNemar Test and the Bland-Altman method were used for data analysis.
\end{abstract}

Results: REEm was significantly lower $(P<0.05$ or $P<0.01)$ than REEe from equations, except for Liu's, Liu's-s, Owen, Owen-s and Mifflin in men and Liu's and Owen in women. REEe calculated by ideal body weight was significantly higher than REEe calculated by current body weight $(P<0.01)$, the only exception being Harris-Benedict equation in men. Bland-Altman analysis showed that the Owen equation with current body weight generated the least bias. The biases of REEe from Owen with ideal body weight and Mifflin with both current and ideal weights were also lower.

Conclusions: Liu's, Owen, and Mifflin equations are appropriate for the prediction of REE in young Chinese adults. However, the use of ideal body weight did not increase the accuracy of REEe.

Keywords: Resting energy expenditure, Indirect calorimetry, Ideal body weight, Predictive equation

\section{Background}

Resting energy expenditure (REE) is the largest component of total daily energy expenditure, accounting for $60 \%$ to $75 \%$ of total expenditure [1]. It represents the metabolic status of body cell mass in both the normal and pathological states. Measuring REE accurately is important for dietary therapy and nutrition support therapy. The metabolic cart is the standard procedure to measure REE. However, this procedure is time consuming, expensive, and usually unavailable because of the requirement for measuring respiratory exchange. More

\footnotetext{
* Correspondence: wendyhu67@21cn.com

${ }^{1}$ Department of Clinical Nutrition, West China Hospital of Sichuan University, Number 37 Guoxuexiang Road, Chengdu 610041, China

Full list of author information is available at the end of the article
}

than 100 predictive equations have been developed [2-4] in order to circumvent this procedure and reduce the variability between measurements. These equations are based upon regressive analysis of body weight, height, sex, and age, or analysis of some independent variables, such as fat free mass, fat mass, body surface area, and total body potassium level [5]. However, these predictive equations are not always accurate in reflecting true REE, because they cannot completely reveal the relationship between the chosen variables and the actual resting energy expenditure in each individual $[1,6]$. Since most equations were developed from research in healthy subjects, it might not be appropriate to use them in patients. Recent studies in patients with different diseases demonstrated that predictive REE were about $10 \%$ 
higher than REE measured by indirect calorimetry (IC) $[7,8]$. In addition, it is not appropriate to apply predictive equations in all kinds of patients $[9,10]$ because of increasing REE under pathological status [11,12]. It is also proposed that using ideal body weight instead of current body weight may increase the accuracy of the estimation in critically ill patients [13].

Most of the predictive equations were developed from studies in Caucasian people, and very few were from studies of Asians [14]. In order to determine the predictive equation most appropriate for the Chinese population, we carried out this study to compare REE calculated by five commonly used predictive equations with REE measured by IC.

For the majority of European public nutrition and clinical nutrition doctor or dietitian, to select one of the most appropriate, the minimum error prediction formula to predict an individual's energy requirements are the most important. In view of the present conclusions of the study on energy requirements is not unified, we hope that our study can provide a reference. $[15,16]$.

\section{Methods \\ Subjects}

The subjects were undergraduates at Sichuan University, Chengdu, China. Inclusion criteria were: age between 18 and 25 years old, having healthy living habits (eating three punctual meals daily, sleeping and exercising regularly, no smoking, no drinking of alcohol). Exclusion criteria were: having diseases that affect the measurement of gas exchange and body metabolism, such as asthma, chronic obstructive pulmonary disease, pneumothorax, upper respiratory tract infection, fever, cancer, hyperthyroidism, diabetes mellitus, hypertension, kidney disease and so on. Forty-three subjects (age, $22.9 \pm 2.0$ years; 21 men (22.4 \pm 1.0 years), and 22 women $(23.4 \pm 2.6$ years) were included in this study.

\section{Measurement of REE}

REE was measured (REEm) in a thermo neutral environment by an open circuit indirect calorimetry (Ultima PFX system, SN: 218000305, Model: 790705-205, Medical Graphics Corp., St. Paul, Minnesota, USA) method with a mask belt, mouthpiece and nose clip. Subjects fasted overnight (12 hours) and rested for 30 minutes before the measurement. Measurements were taken between 8:00 am and 11:00 am. Gas analyzers were calibrated daily before measurement (reference gases $(21 \%$ $\mathrm{O}_{2}$ and $\left.79 \% \mathrm{~N}_{2}\right)$, calibration gases $\left(12 \% \mathrm{O}_{2}, 5 \% \mathrm{CO}_{2}\right.$ and $\left.83 \% \mathrm{~N}_{2}\right)$ ). Pneumotach calibration was also performed daily by using a 3-liter calibration syringe. Measurements were carried out for at least 30 minutes. The steady state period was defined as a five minute period during which the change of average minute oxygen consumption $\left(\mathrm{VO}_{2}\right)$ was less than $10 \%$ and the change of respiratory quotient (RQ) was less than 5\% [17-20]. REEm was determined from $\mathrm{VO}_{2}$ and carbon dioxide production $\left(\mathrm{VCO}_{2}\right)$ using the abbreviated Weir equation [21].

\section{Predicted REE}

The following data were collected to estimate REE (REEe) from the Harris-Benedict (H-B) [2], World Health Organization (WHO) [22], Owen [23,24], Mifflin [25] and Liu's [14] equations (Table 1): height, current body weight, age, and sex. Current body weight and height were measured by a Xiheng doctor's type scale (Wuxi scale machine factory, Wuxi City, Jiangsu Province, China; model: RGZ-120). The ideal body weights of men and women were calculated using the Broca equation (ideal body weight $(\mathrm{kg})=\operatorname{height}(\mathrm{cm})-105)$ and the Broca reformative equation (ideal body weight $(\mathrm{kg})=$ height $(\mathrm{cm})-100)$ [26], respectively. For each predictive equation, two sets of REEe were generated from the two body weight types (ideal and current).

\section{Ethical considerations and statistics}

The study was approved by the Clinical Trial committee of our hospital and was performed in accordance with institutional guidelines and the Declaration of Helsinki. Statistical analysis was performed by the statistical package SPSS Version 13.0 (SPSS Inc.). REE values were expressed as mean \pm SD. The degree of agreement between the predicted and measured REE was evaluated by Bland-Altman limits of agreement analysis [27,28]. The limits of agreement were defined as the mean difference \pm 1.96 standard deviations [29]. REEm were compared

Table 1 Predictive equations to calculate REE

\begin{tabular}{|c|c|c|c|}
\hline \multirow[t]{2}{*}{ Equations } & \multirow[t]{2}{*}{ age } & \multicolumn{2}{|l|}{ REE (kcal/d) } \\
\hline & & Men & Women \\
\hline $\mathrm{H}-\mathrm{B}$ & adult & $66.47+13.75 \times$ BW $+5.0 \times$ Height- $6.76 \times$ Age & $655.1+9.56 \times$ BW $+1.85 \times$ Height $-4.68 \times$ Age \\
\hline $\mathrm{WHO}$ & $18-30 y$ & $15.057 \times B W+692.2$ & $14.818 \times B W+486.6$ \\
\hline Owen & adult & $10.2 \times B W+875$ & $7.18 \times B W+795$ \\
\hline Mifflin & adult & $10 \times B W+6.25 \times$ Height $-5 \times$ Age +5 & $10 \times B W+6.25 \times$ Height $-5 \times$ Age- 161 \\
\hline Liu's & adult & $13.88 \times \mathrm{BW}+4.16 \times$ Height $-3.43 \times$ Age & $13.88 \times$ BW $+4.16 \times$ Height-3.43 $\times$ Age- 112.40 \\
\hline
\end{tabular}

BW,body weight; WHO, World Health Organization; y, years. 
Table 2 Physical characteristics of the subjects $(\overline{\mathbf{x}} \pm \mathbf{s})$

\begin{tabular}{lccc}
\hline & Men (number = 21) & Women (number = 22) & Total (number=43) \\
\hline Age(years) & $22.4 \pm 1.0$ & $23.4 \pm 2.6$ & $22.9 \pm 2.0$ \\
Current body weight $(\mathrm{kg})$ & $64.2 \pm 9.3^{\mathrm{a}}$ & $49.0 \pm 2.9^{\mathrm{a}}$ & $56.5 \pm 10.9$ \\
Ideal body weight $(\mathrm{kg})$ & $69.7 \pm 8.7^{\mathrm{a}}$ & $59.0 \pm 5.8^{\mathrm{a}}$ & $64.2 \pm 9.1$ \\
Height $(\mathrm{cm})$ & $171.3 \pm 7.9^{\mathrm{a}}$ & $159.0 \pm 5.8^{\mathrm{a}}$ & $165.0 \pm 9.2$ \\
$\mathrm{BMI}\left(\mathrm{kg} / \mathrm{m}^{2}\right)$ & $21.8 \pm 2.2^{\mathrm{a}}$ & $19.4 \pm 1.7^{\mathrm{a}}$ & $20.6 \pm 2.3$ \\
\hline
\end{tabular}

${ }^{\mathrm{a}}$ Significantly different between subjects of different sex $(P<0.01)$. BMI, body mass index.z.

separately to two sets of REEe generated from ideal and current body weight using each equation. The estimated accuracy was defined as the percentage of the subjects whose REEe was within $\pm 10 \%$ of REEm. Overestimation and underestimation were defined as $>10 \%$ and $<10 \%$ of REEm, respectively $[1,30]$, and were reported as percentage of subjects. Differences between REEe and REEm were analyzed by Student's $t$ test for paired samples. The accuracy of the different predictive equations and of the two kinds of body weight were compared by using the Wilcoxon Signed Ranks Test and $\chi^{2}$ test (McNemar Test) for nonparametric samples. $P<0.05$ was defined as statistically significant.

\section{Results}

Comparison between REEm and REEe and between REEe calculated by two sets of body weight

Forty-three subjects were recruited in this study. Physical characteristics of the subjects are presented in
Table 2. The average body mass index (BMI) was $20.6 \mathrm{~kg} / \mathrm{m}^{2}$. The means and standard deviations of REEm and REEe are presented in Table 3. The mean of REEm was $1,384.6 \mathrm{kcal} /$ day in men and $1,094 \mathrm{kcal} /$ day in women. There was no significant difference between REEm and REEe calculated by Liu's-current body weight in male, or female, or total subjects, REEe by Liu's-ideal body weight (Liu's-s) in male, REEe by Owen-current body weight in male, or female, or total subjects, REEe by Owen-ideal body weight (Owen-s) in male or all subjects, and REEe by Mifflin-current body weight in men. REEm was significantly lower $(P<0.01)$ than REEe calculated by $\mathrm{H}$-B-current body weight in male or female or total subjects, REEe by H-B-ideal body weight (H-B-s) in male, female or total, REEe by WHO-current body weight in male, female $(P=0.019)$ or total, REEe by WHO-ideal body weight (WHO-s) in male, female, or total, REEe by Liu's-s in female or total, REEe by Owen-s in female, REEe by Mifflin in female or total, and REEe

Table 3 Comparison between measured REE (REEm) and predicted REE (REEe) ( $\overline{\mathbf{x}} \pm \mathbf{s})$

\begin{tabular}{|c|c|c|c|c|c|c|}
\hline \multirow[t]{2}{*}{ Methods } & \multicolumn{6}{|l|}{ REE (kcal/d) } \\
\hline & Men (number $=21$ ) & $P$ value $^{\mathrm{a}}$ & Women (number $=22$ ) & $P$ value $^{\mathrm{a}}$ & Total (number $=43$ ) & $P$ value $^{a}$ \\
\hline IC & $1384.6 \pm 285.4$ & - & $1094.6 \pm 238.1$ & - & $1236.3 \pm 297.7$ & - \\
\hline $\mathrm{H}-\mathrm{B}$ & $1657.1 \pm 157.1$ & 0.001 & $1309.0 \pm 64.6$ & 0.000 & $1479.0 \pm 211.8$ & 0.000 \\
\hline $\mathrm{H}-\mathrm{B}-\mathrm{S}$ & $1589.1 \pm 102.4$ & 0.004 & $1404.2 \pm 67.0$ & 0.000 & $1494.5 \pm 126.4$ & 0.000 \\
\hline$P$ value ${ }^{b}$ & 0.007 & - & 0.000 & - & 0.376 & - \\
\hline WHO & $1659.4 \pm 140.1$ & 0.000 & $1213.3 \pm 87.8$ & 0.019 & $1431.2 \pm 253.2$ & 0.000 \\
\hline WHO-s & $1741.2 \pm 131.1$ & 0.000 & $1360.8 \pm 86.2$ & 0.000 & $1546.6 \pm 221.2$ & 0.000 \\
\hline$P_{\text {value }}^{b}$ & 0.003 & - & 0.000 & - & 0.000 & - \\
\hline Liu's & $1452.7 \pm 158.8$ & 0.295 & $1149.5 \pm 99.8$ & 0.256 & $1297.6 \pm 201.3$ & 0.121 \\
\hline Liu's-s & $1527.9 \pm 138.9$ & 0.054 & $1287.6 \pm 105.1$ & 0.019 & $1405.0 \pm 171.7$ & 0.000 \\
\hline Pvalue ${ }^{b}$ & 0.004 & - & 0.000 & - & 0.000 & - \\
\hline Owen & $1347.2 \pm 152.8$ & 0.508 & $1147.1 \pm 42.6$ & 0.285 & $1244.9 \pm 149.2$ & 0.816 \\
\hline Owen-s & $1386.3 \pm 117.9$ & 0.977 & $1218.6 \pm 41.8$ & 0.019 & $1300.5 \pm 121.2$ & 0.102 \\
\hline Pvalue & 0.010 & - & 0.000 & - & 0.000 & - \\
\hline Mifflin & $1495.8 \pm 146.6$ & 0.085 & $1206.2 \pm 88.0$ & 0.028 & $1347.6 \pm 188.6$ & 0.006 \\
\hline Mifflin-s & $1550.0 \pm 127.8$ & 0.021 & $1305.7 \pm 94.9$ & 0.000 & $1425.0 \pm 166.0$ & 0.000 \\
\hline Pvalue ${ }^{b}$ & 0.003 & - & 0.000 & - & 0.000 & - \\
\hline
\end{tabular}

${ }^{\mathrm{a}} P$ value of comparison between REEm and REEe; ${ }^{\mathrm{b}} P$ value of comparison of REEe between ideal body weight and current body weight; end of the predictive equations' name plus '-s' means that REE was calculated by ideal body weight, otherwise by current body weight. H-B, Harris-Benedict; IC, indirect calorimetry; REE, resting energy expenditure; REEe, estimated REE; REEm, measured REE; WHO, World Health Organization. 
Table 4 The accuracy rates of REEe calculated by current body weight and ideal body weight

\begin{tabular}{|c|c|c|c|c|c|c|}
\hline \multirow[t]{3}{*}{ Methods } & \multicolumn{6}{|c|}{ The state of accuracy } \\
\hline & \multicolumn{2}{|c|}{ Underestimation } & \multicolumn{2}{|c|}{ Accurateness } & \multicolumn{2}{|c|}{ Overestimation } \\
\hline & Men & Women & Men & Women & Men & Women \\
\hline $\mathrm{H}-\mathrm{B}$ & $4.76 \%$ & $4.55 \%$ & $28.57 \%$ & $31.82 \%$ & $66.67 \%$ & $63.64 \%$ \\
\hline$H-B-s^{a}$ & $9.52 \%$ & $0.00 \%$ & $28.57 \%$ & $22.73 \%$ & $61.90 \%$ & $77.27 \%$ \\
\hline WHO & $4.76 \%$ & $9.09 \%$ & $28.57 \%$ & $50.00 \%$ & $66.67 \%$ & $40.91 \%$ \\
\hline WHO-s & $9.52 \%$ & $4.55 \%$ & $14.29 \%$ & $27.27 \%$ & $76.19 \%$ & $68.18 \%$ \\
\hline Liu's & $23.81 \%$ & $22.73 \%$ & $42.86 \%$ & $45.45 \%$ & $33.33 \%$ & $31.82 \%$ \\
\hline Liu's-s & $9.52 \%$ & $4.55 \%$ & $42.86 \%$ & $27.27 \%$ & $47.62 \%$ & $68.18 \%$ \\
\hline Owen & $38.10 \%$ & $22.73 \%$ & $38.10 \%$ & $45.45 \%$ & $23.81 \%$ & $31.82 \%$ \\
\hline Owen-s & $19.05 \%$ & $9.09 \%$ & $57.14 \%$ & $40.91 \%$ & $23.81 \%$ & $50.00 \%$ \\
\hline Mifflin & $9.52 \%$ & $18.18 \%$ & $47.62 \%$ & $36.36 \%$ & $42.86 \%$ & $45.45 \%$ \\
\hline Mifflin-s & $9.52 \%$ & $4.55 \%$ & $42.86 \%$ & $27.27 \%$ & $47.62 \%$ & $68.18 \%$ \\
\hline
\end{tabular}

a End of the predictive equations' name plus '-s' means that REE was calculated by ideal body weight, otherwise by current body weight. H-B, Harris-Benedict; REEe, estimated resting energy expenditure; WHO, World Health Organization.

by Mifflin-ideal body weight (Mifflin-s) in male $(P=0.021)$ or female or total subjects.

REEe calculated by current and ideal body weight were also compared (Table 3). For each equation, the REEe calculated by ideal body weight were all significantly higher than those calculated by current body weight $(P<0.01)$ in both male and female groups. The only exception was the H-B equation in the male group. REEe calculated by ideal body weight was significantly lower than that calculated by current body weight $(P<0.01)$ in this group.

\section{Accuracy of REEe}

The estimation accuracy was defined as the percentage of the subjects whose REEe was within $\pm 10 \%$ of REEm. Overestimation or underestimation was defined as $>10 \%$ or $<10 \%$ of REEm, respectively. Each REEe value was transformed into one of three categories, underestimated, accurate, and overestimated. The percentage of underestimated, accurate, and overestimated subjects for each equation is presented in Table 4. The Wilcoxon Signed Ranks Test was used to compare the accuracy rates between REEe-ideal body weight and REEe-current body weight. The results are presented in Table 5 . In men, significantly different accuracy rates between two weight sets $(P<0.05)$ were found when Liu's and Owen equations were used to calculate REEe. In women, all five equations had significantly different accuracy rates between the two weight sets $(P<0.05$ or $P<0.01)$.

The overestimated percentage amalgamated with underestimated percentage to form an inaccurate percentage, and was compared to the accurate percentage for each equation by the McNemar Test. In both sex groups, using ideal body weight did not decrease the inaccurate rates of REEe $(P>0.05)$. Among the five equations, the highest accuracy rate was produced by the Owen equation using ideal body weight in men (57.14\%). Other relatively high accurate rates were from Liu's and Mifflin equations using both ideal and current body weights in men, and from WHO, Liu's, and Owen equations using current body weight in women(Table 4).

The overestimated rates of $\mathrm{H}-\mathrm{B}$ and $\mathrm{WHO}$ using both ideal and current body weight were high, while this rate was low in Liu's and Owen using current body weight (Table 4). The McNemar Test was used to compare the overestimated rates between two equations (Table 6). When using current body weight, the overestimated rates of $\mathrm{H}-\mathrm{B}$ and $\mathrm{WHO}$ were both significantly higher than those of Liu's and Owen $(P<0.01$ or $P<0.05)$ in men, while in women, only the rate of the H-B equation was significantly higher than those of Liu's and Owen equations $(P<0.05)$. When using ideal body weight, the overestimated rates of the H-B and WHO equations were significantly higher than that of the Owen equation in men $(P<0.01)$, and the rate of the WHO equation was significantly higher than that of Liu's equation $(P<0.05)$, while in women, only the rate of the $\mathrm{H}-\mathrm{B}$ equation was significantly higher than that of the Owen equation $(P<0.05)$.

\section{Bias and precision}

Bland-Altman limits of agreement analysis was used to determine the extent of error for each predictive equation by comparing it to REEm. For the entire study group, the lowest mean difference between REEm and REEe was found in the Owen prediction equation with

Table 5 Comparison of accuracy rates between REEe calculated by current body weight and REEe by ideal body weight

\begin{tabular}{|c|c|c|c|c|c|c|}
\hline \multirow[t]{2}{*}{ Equations } & \multicolumn{3}{|c|}{$P$ value with Wilcoxon Signed Ranks Test } & \multicolumn{3}{|c|}{$P$ value with McNemar Test } \\
\hline & Men & Women & Total & Men & Women & Total \\
\hline $\mathrm{H}-\mathrm{B}$ & 0.157 & 0.046 & 0.414 & 1.000 & 0.625 & 0.688 \\
\hline WHO & 0.564 & 0.008 & 0.011 & 0.250 & 0.125 & 0.021 \\
\hline Liu's & 0.034 & 0.001 & 0.000 & 1.000 & 0.388 & 0.503 \\
\hline Owen & 0.046 & 0.008 & 0.001 & 0.125 & 1.000 & 0.549 \\
\hline Mifflin & 0.564 & 0.005 & 0.007 & 1.000 & 0.727 & 0.549 \\
\hline
\end{tabular}

H-B, Harris-Benedict; REEe, estimated resting energy expenditure; WHO, World Health Organization. 
Table 6 Comparison of overestimated rates between equations

\begin{tabular}{lccc}
\hline $\begin{array}{l}\text { The pair of } \\
\text { equations }\end{array}$ & \multicolumn{3}{l}{$\boldsymbol{P}$ value with McNemar Test } \\
\cline { 2 - 4 } & Men & Women & Total \\
\hline H-B \& Liu's & 0.016 & 0.016 & 0.000 \\
H-B \& Owen & 0.004 & 0.016 & 0.000 \\
H-B-s \& Liu's-s & 0.375 & 0.500 & 0.125 \\
H-B-s \& Owen-s & 0.008 & 0.031 & 0.000 \\
WHO \& Liu's & 0.016 & 0.500 & 0.004 \\
WHO \& Owen & 0.004 & 0.500 & 0.001 \\
WHO-s \& Liu's-s & 0.031 & 1.000 & 0.031 \\
WHO-s \& Owen-s & 0.001 & 0.125 & 0.000 \\
\hline
\end{tabular}

${ }^{a}$ End of the predictive equations' name plus '-s' means that REE was calculated by ideal body weight, otherwise by current body weight. $\mathrm{H}-\mathrm{B}$, Harris-Benedict; WHO, World Health Organization. current body weight (mean difference: $-8.6 \mathrm{kcal} /$ day); however, the extent of error was between $-480.7 \mathrm{kcal}$ and $+463.5 \mathrm{kcal}$ daily (See in Figure 1 ). This mean difference was also lower in Owen with ideal body weight and Liu's with current body weight. The mean difference between REEe and REEm, limits of agreement, and standard error of the limits of agreement are presented in Table 7.

\section{Discussion}

This study used an indirect calorimetry method to measure REE in 43 Chinese young healthy normal weight adults (age 22.9 \pm 2.0 years) and compared the results with REEe generated from five predictive equations. The data suggest that most equations cannot accurately reflect REE in this study group. The source of the bias
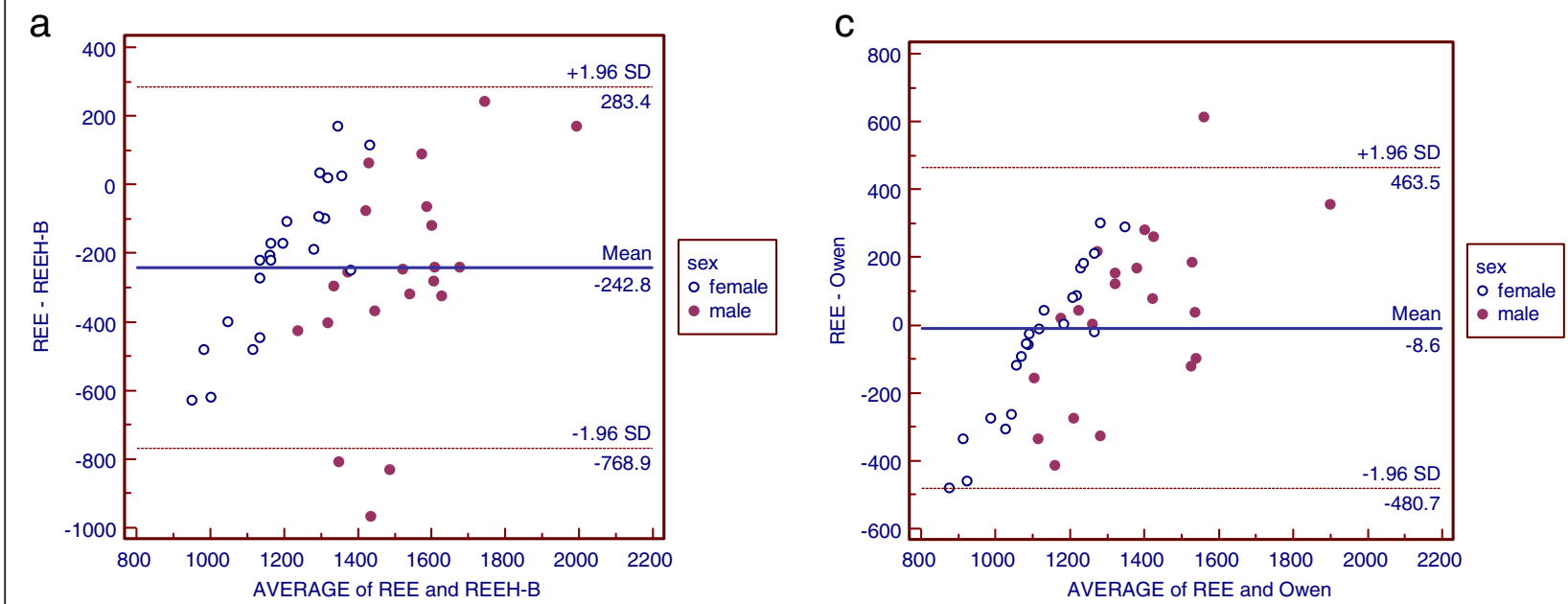

b
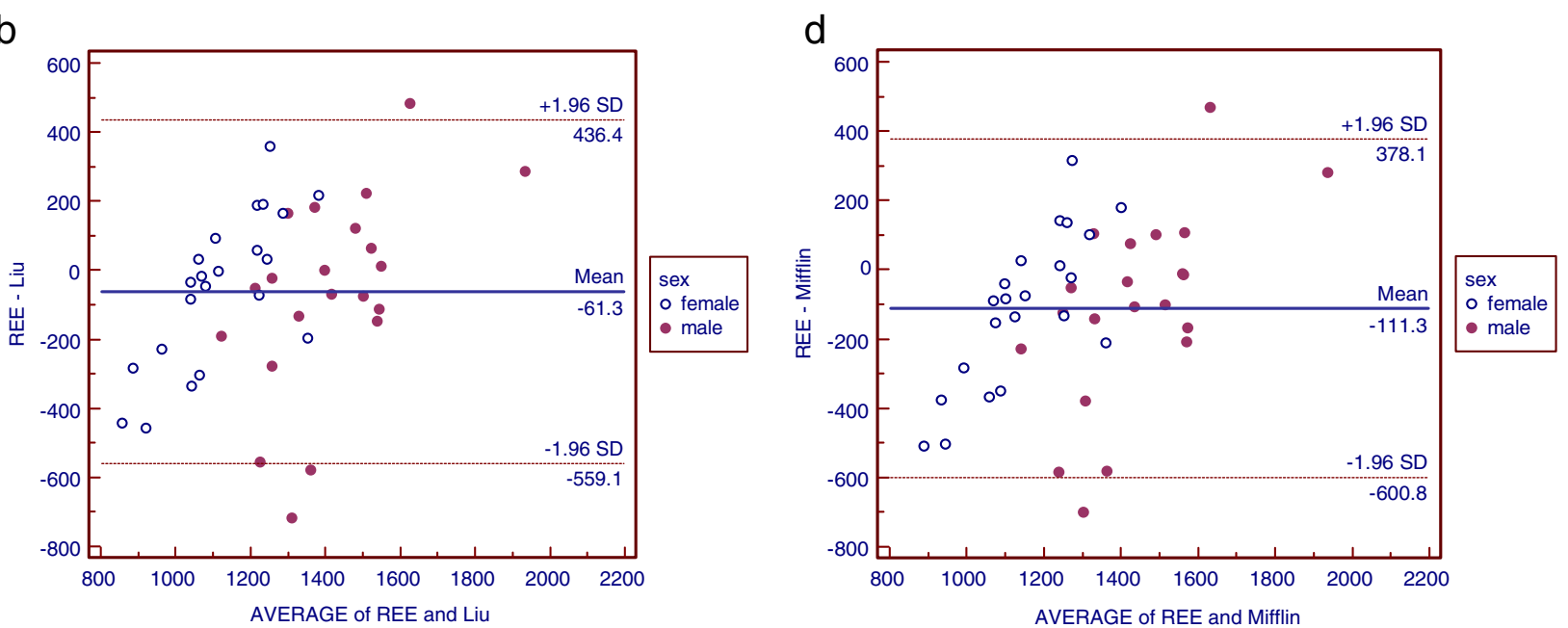

Figure 1 Bland-Altman plots describing agreement between REEm and REEe from five equations and two body weight. The differences of the REEm and REEe are plotted against their means. REEe, estimated resting energy expenditure; REEm, measured resting energy expenditure. 
Table 7 Limits of agreement between REEm and REEe

\begin{tabular}{|c|c|c|c|c|}
\hline \multirow[t]{2}{*}{$\begin{array}{l}\text { The equations } \\
\text { for REEe }\end{array}$} & \multirow{2}{*}{$\begin{array}{l}\text { Mean difference } \\
\text { REEe-REEm } \\
\text { (kcal/day) }\end{array}$} & \multirow{2}{*}{$\begin{array}{l}\text { Limits of agreement } \\
\text { (mean difference } \\
\pm 1.96 \text { SD) (kcal/day) }\end{array}$} & \multicolumn{2}{|c|}{$\begin{array}{l}\text { Standard error for the limits of agreement } \\
\text { (95\% confidence interval for the bias) (kcal/day) }\end{array}$} \\
\hline & & & Lower limits & Upper limits \\
\hline $\mathrm{H}-\mathrm{B}$ & 242.8 & -283.4 to 768.9 & 160.2 & 325.4 \\
\hline$H-B-s^{a}$ & 258.2 & -252.3 to 768.8 & 178.1 & 338.4 \\
\hline WHO & 194.9 & -330.9 to 720.7 & 112.4 & 277.5 \\
\hline WHO-s & 310.3 & -248.6 to 869.3 & 222.6 & 398.1 \\
\hline Liu's & 61.3 & -436.4 to 559.1 & -16.8 & 139.5 \\
\hline Liu's-s & 168.7 & -373.1 to 710.5 & 83.6 & 253.8 \\
\hline Owen & 8.6 & -463.5 to 480.7 & -65.5 & 82.7 \\
\hline Owen-s & 64.2 & -430.0 to 558.4 & -13.4 & 141.8 \\
\hline Mifflin & 111.3 & -378.1 to 600.8 & 34.5 & 188.2 \\
\hline Mifflin-s & 188.8 & -333.0 to 710.6 & 106.9 & 270.7 \\
\hline
\end{tabular}

and of the predictive equations' name plus '-s' means that REE was calculated by ideal body weight, otherwise by current body weight. $\mathrm{H}-\mathrm{B}$, Harris-Benedict; REEe, estimated resting energy expenditure; REEm, measured resting energy expenditure; WHO, World Health Organization.

may be derived from equation limitations, the subjects' characteristics, and measurement error. Several strategies were employed in this study to reduce the bias. The study group was representative of healthy Chinese undergraduates. REE, body weight, and height were all measured in well-controlled settings using current state of the art methodologies.

The Bland-Altman limits of agreement analysis showed that REEe generated from Owen and Mifflin equations agreed best with REEm (Figure 1). A recent study [31] also used the Bland and Altman method to analyze the agreement between REEe and REEm. It indicated that the Owen equation could be used to predict REE in young women with normal body weight. In our study, the average BMIs of men and women were $21.8 \pm 2.2 \mathrm{~kg} / \mathrm{m}^{2}$ and $19.4 \pm 1.7 \mathrm{~kg} / \mathrm{m}^{2}$, respectively, and the range was $18.5 \mathrm{~kg} / \mathrm{m}^{2}$ to $24.9 \mathrm{~kg} / \mathrm{m}^{2}$, except for one male subject who had a $27.1 \mathrm{~kg} / \mathrm{m}^{2}$ BMI. In the original paper on the Mifflin equation, the authors selected 264 normal weight and 234 obese healthy subjects and found that body composition and body-weight distribution did not significantly affect REEe from various equations [25]. A recent study suggested that the Mifflin equation was valid in REE prediction in healthy Puerto Rican adults [32]. Another study in Belgian women showed that the Mifflin equation was a reliable tool to predict REE across a wide variety of body weight (BMI 18.5 to $50 \mathrm{~kg} / \mathrm{m}^{2}$ ) [33]. In our study, we found that the Mifflin equation matched well with REEm. Also, we conclude that the Owen and Mifflin equations are more suitable to predict REE in this specific population.

Estimation accuracy was defined as the percentage of subjects whose REEe was within $\pm 10 \%$ of REEm, considering it as a clinically relevant difference $[4,30]$. This error limit was accepted empirically because calorimetry measurement error is within $\pm 5 \%$. We also used $\pm 10 \%$ of
REEm to define accuracy; estimations above 10\% of REEm were defined as overestimated, and those below $10 \%$ of REEm were defined as underestimated.

In our study, REEe were significantly higher than REEm. The exceptions were REEe from Liu's, Liu's-s, Owen, Owen-s, and Mifflin in men and Liu's and Owen in women. This is not unexpected because both H-B and WHO equations were derived from research in subjects with a wide age range, but our study only included a limited number of young subjects. H-B was developed from research in healthy normal weight white men $(\mathrm{n}=136$, age 16 to 63 years $)$ and women $(\mathrm{n}=103$, age 15 to 74 years), and had been adapted to be used in age groups from 21 to 70 years old [2]. The H-B equation is the most widely used equation in basal metabolic rate estimation. However, according to the original publication, the measurements were taken during the resting state, not under basal conditions [30]. In our study, we also measured REEm under resting conditions but REEe calculated by $\mathrm{H}-\mathrm{B}$ equations using both current body weight and ideal body weight were still higher than REEm in both sexes. In a study about anorexia nervosa, the H-B equation overestimated REE; the reason might be that the patients' BMIs were below normal [34]. Therefore, it can be accepted that the H-B equation overestimates REE in a young Chinese population.

The WHO equation was developed from research in young Europeans, most of whom were military and police recruits, with $45 \%$ of Italian descent [30]. In our study, the subjects were Chinese youth. This might explain the low accuracy rates of REE predicted by WHO in men $(28.57 \%)$ in our study. However, the accuracy rate in women was $50.0 \%$; maybe, the reason is that the subjects of this research comprised 2,279 men but only 247 women [30] and there was some bias in women per $s e$. So the WHO equation is suitable for a European 
population, but not for Asians, especially, at least, not for Chinese men.

Liu's equation was developed from research in a Chinese population. Previous studies have confirmed that Liu's equation is the most appropriate one for predicting REE in healthy Chinese subjects [35]. In our study, the accuracy rates were $42.86 \%$ in men and $45.45 \%$ in women when using current body weight, and $42.86 \%$ in men when using ideal body weight. Compared with most other equations, these accuracy rates were higher. So, Liu's equation is suitable for predicting REE in Chinese young subjects.

The Owen equation was derived from 44 healthy lean and obese women between 18 to 65 years old and 60 lean and obese men between 18 to 82 years old [23,24]. The Mifflin equation was derived from 498 healthy subjects (247 women, 251 men, 19 to 78 years old, among whom 264 were normal weight, and 234 obese) [25]. These two equations are commonly used in clinical practice. The accuracy rates of the Owen equation are $38.10 \%$ in men and $45.45 \%$ in women and the Mifflin equation had $47.62 \%$ and $36.36 \%$ accuracy rates in men and women, respectively (Table 4). The accuracy rates of these two equations are comparable to those of Liu's. In addition, the Bland and Altman agreement analysis (Figure 1) indicated that these two equations had a lower extent of error in the study group. Moreover, in a study of Brazilian overweight and obese adults, the Mifflin equation had the best correlation with IC [36]. Thus, the Owen equation and the Mifflin equation could also be used to predict REE in Chinese young healthy normal weight adults.

Researchers normally use current body weight when applying the equations to predict REE, and they also define certain body types to meet the application range of the equations. However, in a real clinical setting, ideal body weight is often used in order to make subjects with abnormal body weight normal. Several studies showed that REE predicted by ideal body weight was more accurate than that predicted by current body weight $[13,37,38]$. In our study, by using Wilcoxon Signed Ranks Test, we found that current and ideal body weights generated obviously different accuracy rates of REEe. However, when we amalgamated the overestimated and underestimated subjects together as inaccurate, and analyzed the data, again using the McNemar Test, we found that there was no significant difference in the inaccuracy rates between two weight sets. In fact, REEe predicted by ideal body weight were higher than those predicted by current body weight. It seems that using ideal body weight did not increase the accuracy of REEe, except for the Owen equations in men. However, in a Brazilian study in patients with short bowel syndrome, researchers found that compared to current body weight, ideal body weight could increase the accuracy of REEe when using the H-B equation [39]. The difference between the two studies was probably due to the fact that patients with short bowel syndrome always had severe mixed-type malnutrition and low current body weight, so predicting REEe by using ideal body weight had considerable accuracy. However, in our study, ideal body weight was higher than current body weight in both sexes, while REEe from the current body weight was higher than REEm, so ideal body weight could not increase the accuracy of REEe. It may be that the normal average BMI of the subjects influenced the results. Some studies suggested using ideal body weight when predicting REE in obese subjects [40], while others preferredcurrent body weight in obese subjects [41]. Consequently, in our future study, we may need to classify the body type and research purpose in the prediction of REE by using ideal body weight.

We used the Bland and Altman method to assess the agreement between measured and predicted REE. Bland and Altman represented that, when comparing two clinical assessment methods, if neither of them can provide an unequivocally correct measurement, then the researchers should analyze the degree of their agreement instead of correlation or regression [42]. Still, many studies gave the correlation coefficient $(r)$ between the results of two measurement methods as an indicator of agreement. Bland and Altman emphasized that $r$ measures the strength of a relationship between two variables, not the agreement. In addition, a change in the scale of measurement does not affect the strength of correlation, but it affects the agreement [1]. For instance, if a REE predictive equation yields results exactly two times higher than REE obtained by IC, then correlation analysis would show one straight line with $r=1$, but the two measurements would not agree. Furthermore, the strength of the correlation between REEm and REEe increases when the ranges of REE are wider [43]. Regression analysis can be used to compare measurement methods because it attempts to predict the measured values (containing errors) from the observed values (considered without errors). For easier interpretation of the results, the same method should be used when assessing the agreement between two methods of clinical measurement [1].

\section{Conclusions}

We found that $\mathrm{H}-\mathrm{B}$ and WHO equations cannot be used to predict REE in Chinese young healthy normal weight adults. Liu's, Owen, and Mifflin equations had higher accuracy rates in estimating REE. Bland and Altman analysis further suggested that Owen and Liu's equations had a lower bias and agreed better with REEm. Taken together, we conclude that Liu's, Owen and Mifflin 
equations can be used to predict REE in Chinese young healthy normal weight adults.

Ideal body weight is often used in the equations to predict REE in clinic settings and many studies proved that ideal body weight could increase the accuracy of predicted REE. However, in our study, ideal body weight did not increase the accuracy rates.

\section{Abbreviations}

BMI: Body mass index; H-B equation: Harris-Benedict equation; IC: Indirect calorimetry; REE: Resting energy expenditure; REEe: Predicted resting energy expenditure; REEm: Measured resting energy expenditure; $\mathrm{VO}_{2}$ : Oxygen consumption; $\mathrm{VCO}_{2}$ : Carbon dioxide production; WHO: World Health Organization.

\section{Competing interests}

The authors declare that they have no competing interests.

\section{Authors' contributions}

ZR was responsible for conceiving and designing the study, collecting and analyzing the data, and drafting the report. XW was responsible for revising the report. BL and MW were responsible for technical support during the measurement of REE. WH was responsible for interpreting the data and drafting the report. All authors read and approved the final manuscript.

\section{Acknowledgments}

We acknowledge Yuanyuan Liu (Department of Health Statistics, School of Public Health, Sichuan University) for statistical advice. No author had any financial or personal interest in any company or organization relevant to the field of research in connection with this work.

\section{Author details}

Department of Clinical Nutrition, West China Hospital of Sichuan University, Number 37 Guoxuexiang Road, Chengdu 610041, China. ${ }^{2}$ Center of Gastrointestinal Surgery, West China Hospital of Sichuan University, Number 37 Guoxuexiang Road, Chengdu 610041, China. ${ }^{3}$ Lung Function Laboratory of Department of Respiration, West China Hospital of Sichuan University, Number 37 Guoxuexiang Road, Chengdu 610041, China.

Received: 16 April 2012 Accepted: 25 July 2012

Published: 1 September 2012

\section{References}

1. Melzer K, Laurie Karsegard V, Genton L, Kossovsky MP, Kayser B, Pichard C: Comparison of equations for estimating resting metabolic rate in healthy subjects over 70 years of age. Clin Nutr 2007, 26:498-505.

2. Harris JA, Benedict FG: A Biometric study of human basal metabolism. Proc Natl Acad Sci U S A 1918, 4:370-373.

3. Muller MJ, Bosy-Westphal A, Klaus S, Kreymann G, Luhrmann PM, Neuhauser-Berthold M, Noack R, Pirke KM, Platte P, Selberg O, Steiniger J: World Health Organization equations have shortcomings for predicting resting energy expenditure in persons from a modern, affluent population: generation of a new reference standard from a retrospective analysis of a German database of resting energy expenditure. Am J Clin Nutr 2004, 80:1379-1390.

4. Frankenfield D, Smith JS, Cooney RN: Validation of 2 approaches to predicting resting metabolic rate in critically ill patients. JPEN J Parenter Enteral Nutr 2004, 28:259-264

5. Weijs PJ, Kruizenga HM, van Dijk AE, van der Meij BS, Langius JA, Knol DL, van Schijndel RJS, van Bokhorst-de van der Schueren MA: Validation of predictive equations for resting energy expenditure in adult outpatients and inpatients. Clin Nutr 2008, 27:150-157.

6. Wilms B, Schmid SM, Ernst B, Thurnheer M, Mueller MJ, Schultes B: Poor prediction of resting energy expenditure in obese women by established equations. Metabolism 2010, 59:1181-1189.

7. Boullata J, Williams J, Cottrell F, Hudson L, Compher C: Accurate determination of energy needs in hospitalized patients. J Am Diet Assoc 2007, 107:393-401.
8. Siirala W, Olkkola KT, Noponen T, Vuori A, Aantaa R: Predictive equations over-estimate the resting energy expenditure in amyotrophic lateral sclerosis patients who are dependent on invasive ventilation support. Nutr Metab (Lond) 2010, 7:70-76.

9. da Rocha EE, Alves VG, Silva MH, Chiesa CA, da Fonseca RB: Can measured resting energy expenditure be estimated by formulae in daily clinical nutrition practice? Curr Opin Clin Nutr Metab Care 2005, 8:319-328.

10. Taylor SJ: Predicting resting energy expenditure (REE): misapplying equations can lead to clinically significant errors. e-SPEN, the European eJournal of Clinical Nutrition and Metabolism 2010, 5:e254-e260.

11. Caliyurt O, Altiay G: Resting energy expenditure in manic episode. Bipolar Disord 2009, 11:102-106.

12. Vaisman N, Lusaus M, Nefussy B, Niv E, Comaneshter D, Hallack R, Drory VE: Do patients with amyotrophic lateral sclerosis (ALS) have increased energy needs?J. Neurol Sci 2009, 279:26-29.

13. Zauner A, Schneeweiss B, Kneidinger N, Lindner G, Zauner C: Weightadjusted resting energy expenditure is not constant in critically ill patients. Intensive Care Med 2006, 32:428-434.

14. Liu B, Woo J, Tang N, Ng K, Ip R, Yu A: Assessment of total energy expenditure in a Chinese population by a physical activity questionnaire: examination of validity. Int J Food Sci Nutr 2001, 52:269-282.

15. Ruiz JR, Ortega FB, Rodriguez G, Alkorta P, Labayen I: Validity of resting energy expenditure predictive equations before and after an energy-restricted diet intervention in obese women. PLoS One 2011, 6:e23759.

16. Libere GP, Guastavino S, Escobar MA, De Vito EL: Predictive equations not always overestimate the resting energy expenditure in amyotrophic lateral sclerosis patients. Nutr Metab (Lond) 2011, 8:47.

17. Sherman MS, Pillai A, Jackson A, Heiman-Patterson T: Standard equations are not accurate in assessing resting energy expenditure in patients with amyotrophic lateral sclerosis. JPEN J Parenter Enteral Nutr 2004, 28:442-446.

18. Cadena M, Sacristan E, Infante O, Escalante B, Rodriguez F: Steady state condition in the measurement of $\mathrm{VO}_{2}$ and $\mathrm{VCO}_{2}$ by indirect calorimetry. Conf Proc IEEE Eng Med Biol Soc 2005, 7:7773-7776.

19. Petros $\mathrm{S}$, Engelmann L: Validity of an abbreviated indirect calorimetry protocol for measurement of resting energy expenditure in mechanically ventilated and spontaneously breathing critically ill patients. Intensive Care Med 2001, 27:1164-1168.

20. McClave SA, Spain DA, Skolnick JL, Lowen CC, Kieber MJ, Wickerham PS, Vogt JR, Looney SW: Achievement of steady state optimizes results when performing indirect calorimetry. JPEN J Parenter Enteral Nutr 2003, 27:16-20.

21. Weir JB: New methods for calculating metabolic rate with special reference to protein metabolism. J Physiol 1949, 109:1-9.

22. Alam DS, Hulshof PJ, Roordink D, Meltzer M, Yunus M, Salam MA, van Raaij JM: Validity and reproducibility of resting metabolic rate measurements in rural Bangladeshi women: comparison of measurements obtained by Medgem and by Deltatrac device. Eur I Clin Nutr 2005, 59:651-657.

23. Owen OE, Holup JL, D'Alessio DA, Craig ES, Polansky M, Smalley KJ, Kavle EC, Bushman MC, Owen LR, Mozzoli MA, et al: A reappraisal of the caloric requirements of men. Am J Clin Nutr 1987, 46:875-885.

24. Owen OE, Kavle E, Owen RS, Polansky M, Caprio S, Mozzoli MA, Kendrick ZV, Bushman MC, Boden G: A reappraisal of caloric requirements in healthy women. Am J Clin Nutr 1986, 44:1-19.

25. Mifflin MD, St Jeor ST, Hill LA, Scott BJ, Daugherty SA, Koh YO: A new predictive equation for resting energy expenditure in healthy individuals. Am J Clin Nutr 1990, 51:241-247.

26. Broca PP: Paul Pierre Broca (1824-1880). Obes Rev 2007, 8:277.

27. Bland JM, Altman DG: Applying the right statistics: analyses of measurement studies. Ultrasound Obstet Gynecol 2003, 22:85-93.

28. Altman DG, Bland JM: Measurement in medicine: the analysis of method comparison studies. Statistician 1983, 32:307-317.

29. Dewitte K, Fierens C, Stockl D, Thienpont LM: Application of the BlandAltman plot for interpretation of method-comparison studies: a critical investigation of its practice. Clin Chem 2002, 48:799-801. author reply 801-792.

30. Frankenfield D, Roth-Yousey L, Compher C: Comparison of predictive equations for resting metabolic rate in healthy nonobese and obese adults: a systematic review. J Am Diet Assoc 2005, 105:775-789. 
31. Siervo M, Boschi V, Falconi C: Which REE prediction equation should we use in normal-weight, overweight and obese women? Clin Nutr 2003, 22:193-204

32. de la Torre CL, Ramirez-Marrero FA, Martinez LR, Nevarez C: Predicting resting energy expenditure in healthy Puerto Rican adults. J Am Diet Assoc 2010, 110:1523-1526.

33. Weijs PJ, Vansant GA: Validity of predictive equations for resting energy expenditure in Belgian normal weight to morbid obese women. Clin Nutr 2010, 29:347-351.

34. El Ghoch M, Alberti M, Capelli C, Calugi S, Dalle Grave R: Resting energy expenditure in anorexia nervosa: measured versus estimated. J Nutr Metab 2012, 2012:652932.

35. Leung R, Woo J, Chan D, Tang N: Validation of prediction equations for basal metabolic rate in Chinese subjects. Eur J Clin Nutr 2000, 54:551-554.

36. de Oliveira EP, Orsatti FL, Teixeira O, Maesta N, Burini RC: Comparison of predictive equations for resting energy expenditure in overweight and obese adults. J Obes 2011, 2011:534714.

37. Glynn CC, Greene GW, Winkler MF, Albina JE: Predictive versus measured energy expenditure using limits-of-agreement analysis in hospitalized, obese patients. JPEN J Parenter Enteral Nutr 1999, 23:147-154.

38. Campbell CG, Zander E, Thorland W: Predicted vs measured energy expenditure in critically ill, underweight patients. Nutr Clin Pract 2005, 20:276-780.

39. Araujo EC, Suen VM, Marchini JS, Vannucchi H: Ideal weight better predicts resting energy expenditure than does actual weight in patients with short bowel syndrome. Nutrition 2007, 23:778-781.

40. Barak N, Wall-Alonso E, Sitrin MD: Evaluation of stress factors and body weight adjustments currently used to estimate energy expenditure in hospitalized patients. JPEN J Parenter Enteral Nutr 2002, 26:231-238.

41. Ireton-Jones CS, Turner WW Jr: Actual or ideal body weight: which should be used to predict energy expenditure? J Am Diet Assoc 1991, 91:193-195.

42. Bland JM, Altman DG: Statistical methods for assessing agreement between two methods of clinical measurement. Lancet 1986, 1:307-310

43. Bunce C: Correlation, agreement, and Bland-Altman analysis: statistical analysis of method comparison studies. Am J Ophthalmol 2009, 148:4-6.

doi:10.1186/2047-783X-17-26

Cite this article as: Rao et al:: Comparison of five equations for estimating resting energy expenditure in Chinese young, normal weight healthy adults. European Journal of Medical Research 2012 17:26.

\section{Submit your next manuscript to BioMed Central and take full advantage of:}

- Convenient online submission

- Thorough peer review

- No space constraints or color figure charges

- Immediate publication on acceptance

- Inclusion in PubMed, CAS, Scopus and Google Scholar

- Research which is freely available for redistribution

Submit your manuscript at www.biomedcentral.com/submit
(O) Biomed Central 